\title{
Endocytosis in the uterine epithelium of the mouse
}

\author{
Margaret B. Parr and E. L. Parr \\ Department of Anatomy and Histology, University of Adelaide, \\ Adelaide, South Australia 5001
}

Histological studies have shown that the uterine luminal epithelial cells develop protrusions from their apical surfaces during preimplantation or delayed implantation stages in rats (Warren \& Enders, 1964; Nilsson, 1966; Lööf, Nilsson \& Toss, 1968; Psychoyos \& Mandon, 1971; Nilsson, 1972), mice (Nilsson, 1962; Bergstrom \& Nilsson, 1972, 1973), deer (Aitken, 1975), and women (Nilsson \& Nygren, 1974). The protrusions have been described as 'sea anemone-like formations' (Psychoyos \& Mandon, 1971) or 'fungus-like protrusions' (Nilsson, 1972), and most investigators have suggested that they pinch off from the cells to provide an apocrine secretion for the nourishment of preimplantation embryos in the uterine lumen. However, investigations in the rat have shown that the protrusions are involved in endocytosis, not apocrine secretion (Enders \& Nelson, 1973; Parr \& Parr, 1974): exogenous tracers placed in the uterine lumen were quickly taken up into the large vacuoles which are frequently present in the protrusions, while later the tracers were located in multivesicular and dense bodies within the cells. Enders \& Nelson (1973) have suggested that the protrusions be called pinopods. In this report we present evidence that the protrusions known to occur on mouse uterine epithelial $48 \mathrm{~h}$ cells also mediate endocytosis, and hence are pinopods.

Uteri were obtained from outbred albino mice at about $10.00 \mathrm{~h}, 2$ each on Days 2, 3 and 5 of pregnancy and from 5 mice on Day 4 of normal pregnancy. The day on which the copulatory plug was found in the vagina was designated Day 1 of pregnancy. Small cross-sectional segments of the uterine horns were fixed by immersion in $2.5 \%$ glutaraldehyde for $30 \mathrm{~min}$, followed by $1 \% \mathrm{OsO}_{4}$ for $2 \mathrm{~h}$, both in veronal-acetate buffer (Parr, 1973). Specimens were dehydrated and embedded in epon-araldite. Sections $1.0 \mu \mathrm{m}$ thick were stained with $1 \%$ toluidine blue in $1 \%$ sodium borate for light microscopy. Thin sections for electron microscopy were prepared in the usual manner. To obtain animals in delayed implantation, 8 mice were ovariectomized on Day 3 of pregnancy and given an s.c. injection of $1 \mathrm{mg}$ progesterone/day in peanut oil until Day 10. On Day 10, 5 mice were anaesthetized and $0.05 \mathrm{ml} 3 \%$ ferritin (Nutritional Biochemicals Corp., Cleveland, U.S.A.), purified by centrifugation (Parr \& Parr, 1974) and dissolved in tissue culture medium, was injected into the lumen of one uterine horn of each mouse. Both uterine horns were removed at $15 \mathrm{~min}$ (4 mice) or $60 \mathrm{~min}$ ( 1 mouse) after the ferritin injection and the tissue was processed as described above. The three remaining mice in delayed implantation each received s.c. $0.5 \mu \mathrm{g}$ oestradiol benzoate in peanut oil on Day 8. On Day 10 the ferritin tracer was injected into one uterine horn, and the animals were killed $60 \mathrm{~min}$ later to recover the uterine horns for processing as described above.

We studied many light microscope sections from 10 blocks of uterine tissue from mice on Day 4 of normal pregnancy and from 19 blocks of uterine tissue from mice on Day 10 of delayed implantation. At these times the apical surface of the luminal epithelium exhibited numerous short microvilli, and in some cells larger portions of the apical surface protruded into the lumen. These protrusions frequently contained vacuoles measuring up to $4.5 \mu \mathrm{m}$ in diameter, and similar vacuoles were present in the apical cytoplasm of many cells lacking protrusions. While we have not made a careful quantitative comparison, it seemed that the protrusions were more numerous on Day 10 of delayed implantation than on Day 4 of normal pregnancy. Plate 1 shows a collection of light micrographs of uterine tissue taken at Day 10 of delayed implantation to show how the protrusions could be involved in the formation of an endocytic vacuole. We were unable to find any of these characteristic protrusions in light microscope sections from 12 blocks of tissue from the 6 animals killed on Days 2, 3 or 5 of normal pregnancy, or in sections of 9 blocks of tissue from the 3 mice in delayed implantation given oestrogen $48 \mathrm{~h}$ earlier. 
Evidence of the endocytotic function of the protrusions was obtained by studying the uptake of ferritin from the uterine lumen on Day 10 of delayed implantation. By $15 \mathrm{~min}$ after injection, ferritin was found in the lumen, in the vacuoles within protrusions, and in many of the large vacuoles in the apical cytoplasm of cells lacking pinopods (PI. 2, Figs 13, 14 and 15), and by 60 min ferritin was still present in these areas and also concentrated in dense bodies deeper in the apical cytoplasm ( $\mathrm{Pl}$. 3, Figs 16,17 and 18). Ferritin was also taken up from the lumen into typical $0.2 \mu \mathrm{m}$ coated pinocytotic vesicles, but this latter channel of marker uptake was not frequently observed. There was no obvious ferritin uptake by the uterine epithelium of the 3 mice in delayed implantation and given oestrogen $48 \mathrm{~h}$ earlier.

The pinopods of the mouse uterine epithelium are unlikely to be artefacts of immersion fixation because they carry out endocytosis before fixation. Ferritin from the uterine lumen was rapidly incorporated (15 min) into pinopod vacuoles and large vacuoles in the apical cytoplasm, and later (60 $\mathrm{min}$ ) into dense bodies deeper in the cells. The apical cytoplasmic vacuoles that contained ferritin were comparable in size to the pinopod vacuoles, contained ferritin at essentially the same concentration as the pinopod vacuoles, and were not open to the outside. (Some of the pinopod vacuoles, of course, might still have been open in places to the uterine lumen.) Such evidence of endocytosis would not be produced by poor fixation. In addition, ferritin did not induce the pinopods because they were present in contralateral horns not injected with ferritin as frequently as they were found in ferritin-injected horns.

\section{EXPLANATION OF PLATES}

\section{Plate 1}

This illustration is a composite of light micrographs to show the probable sequence of steps in the formation of endocytotic vacuoles by protrusions from the apical surface of mouse uterine epithelial cells on Day 10 of delayed implantation. At first, a small irregular protrusion appears (Fig. 1); it is larger than the microvilli but does not involve the entire surface of the cell. Frequently, the initial projection from the surface appears near the edge of the cell, adjacent to the intercellular junction. The protrusion enlarges and forms a single, arm-like process seen in various aspects (Figs 2, 3 and 4). Serial sections of the cells in Figs 2, 3 and 4 provided convincing evidence that these images were not the result of sections through the edges of projections similar to those seen in Figs 5, 6 or 7. The arm-like projection then apparently bends over and makes contact with the surface of the cell to form a vacuole (Figs 5,6 and 7). The vacuole passes downward out of the projection and into the apical portion of the cell (Figs 8 and 9). The projection regresses (Fig. 10) and the vacuole shrinks and migrates deeper into the cell (Figs 11 and 12). $\times 1000$.

\section{Plate 2}

Electron micrographs of the apical region of mouse uterine epithelial cells on Day 10 of delayed implantation $15 \mathrm{~min}$ after the injection of ferritin into the uterine lumen. The unlabelled arrows indicate a population of clear vesicles that never contained ferritin.

Fig. 13 shows an endocytotic vacuole, $2.5 \mu \mathrm{m}$ in diameter, within a protrusion extending into the lumen (L). Ferritin $(F)$ is found in the lumen and in the endocytotic vacuole. $\times 32,000$

Fig. 14 shows an endocytotic or pinopod vacuole (PV) deeper in the apical cytoplasm. It contains ferritin and is reduced in size. $\times 32,000$.

Fig. 15 is an enlargement of the vacuole in Fig. 14 to show the ferritin more clearly, $\times 55,000$.

\section{PLATE 3}

Electron micrographs of the mouse uterine epithelium on Day 10 of delayed implantation, 60 min after the injection of ferritin into the lumen.

Fig. 16. A cell which contains a new endocytotic vacuole (PV) and an older dense body (DB). LB indicates lipid bodies or droplets. $\times 9200$.

Fig. 17. Ferritin present in a dense body. $\times 55,000$.

Fig. 18. Ferritin present in an endocytotic vacuole. $\times 55,000$, 

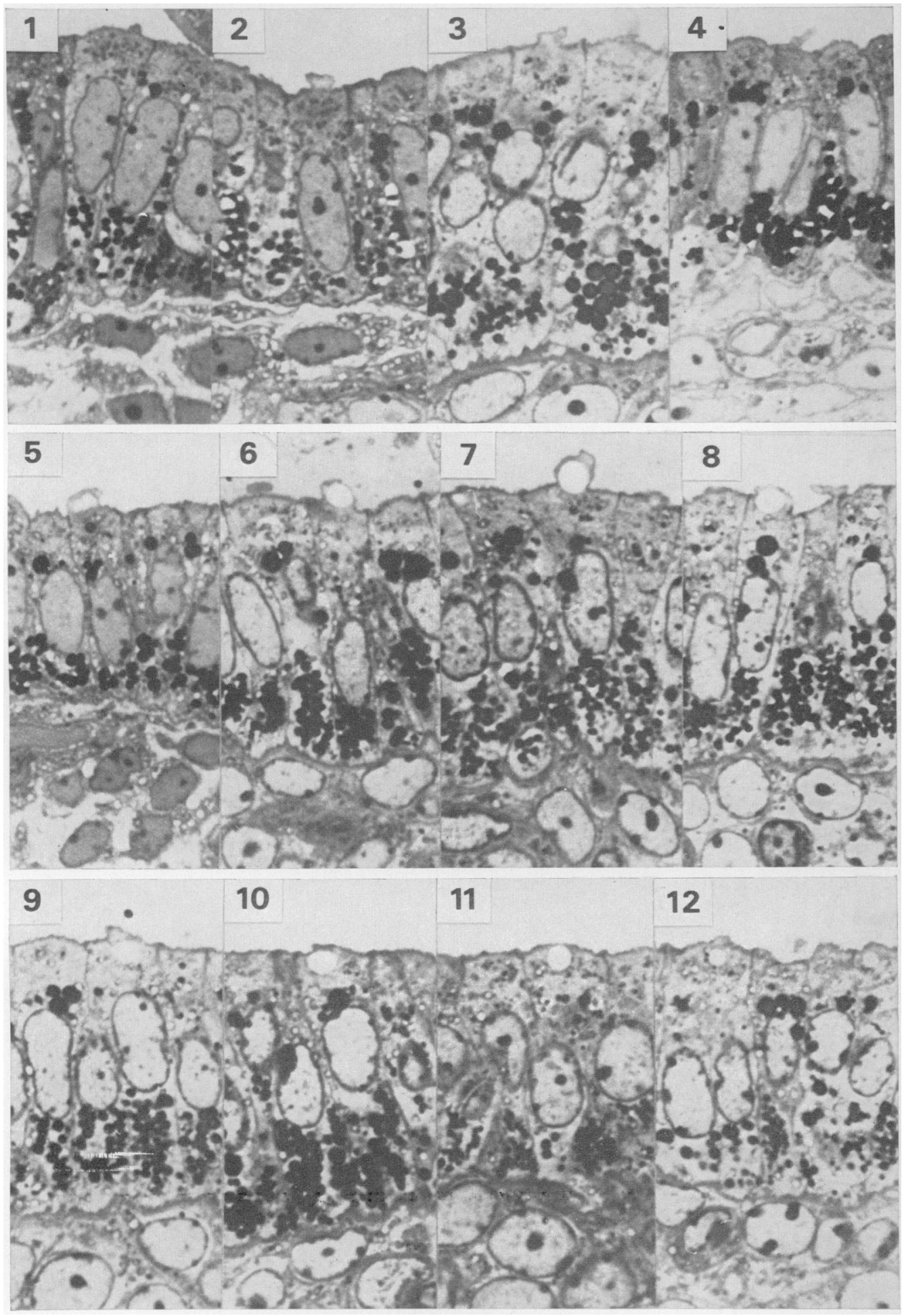
PLATE 2

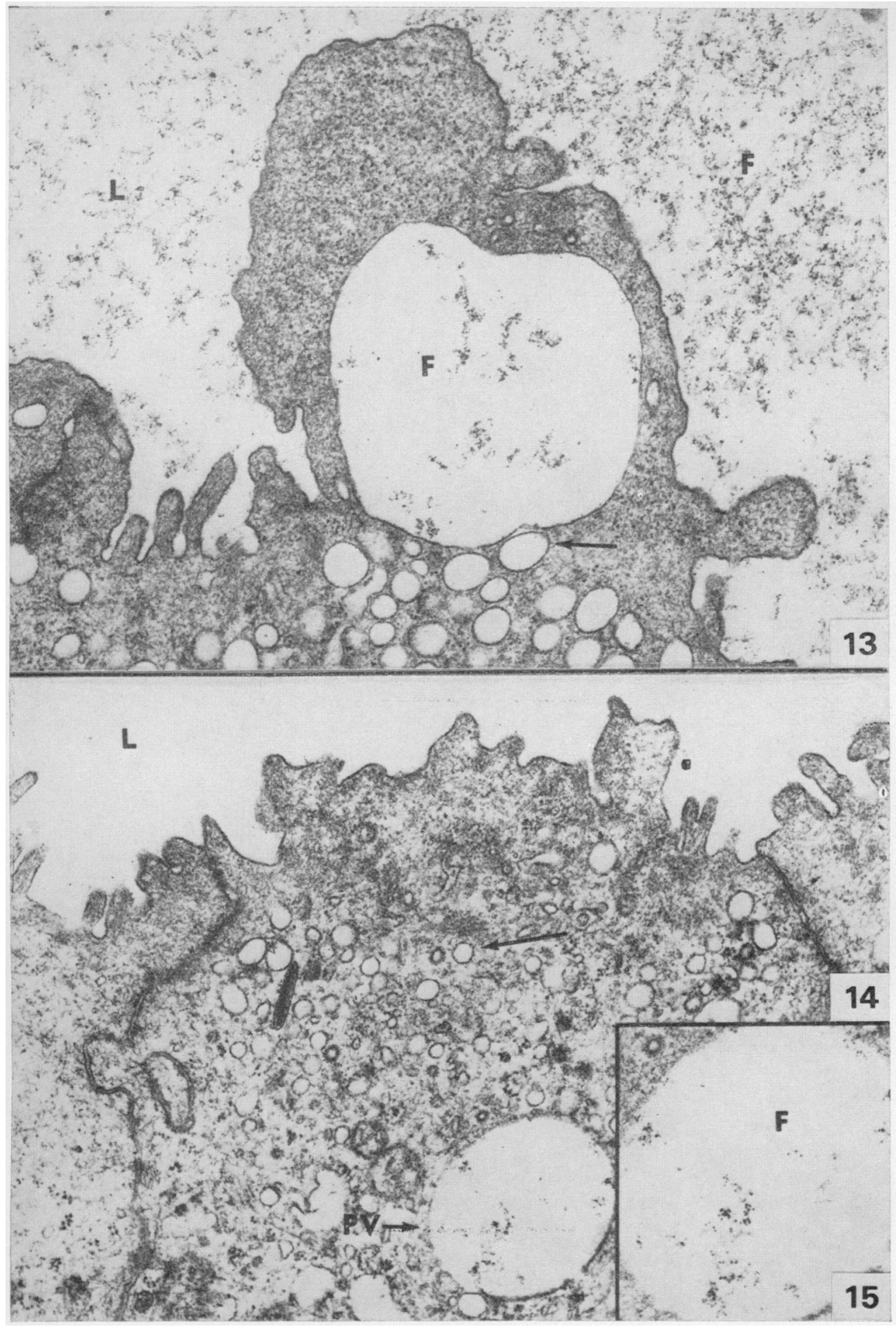




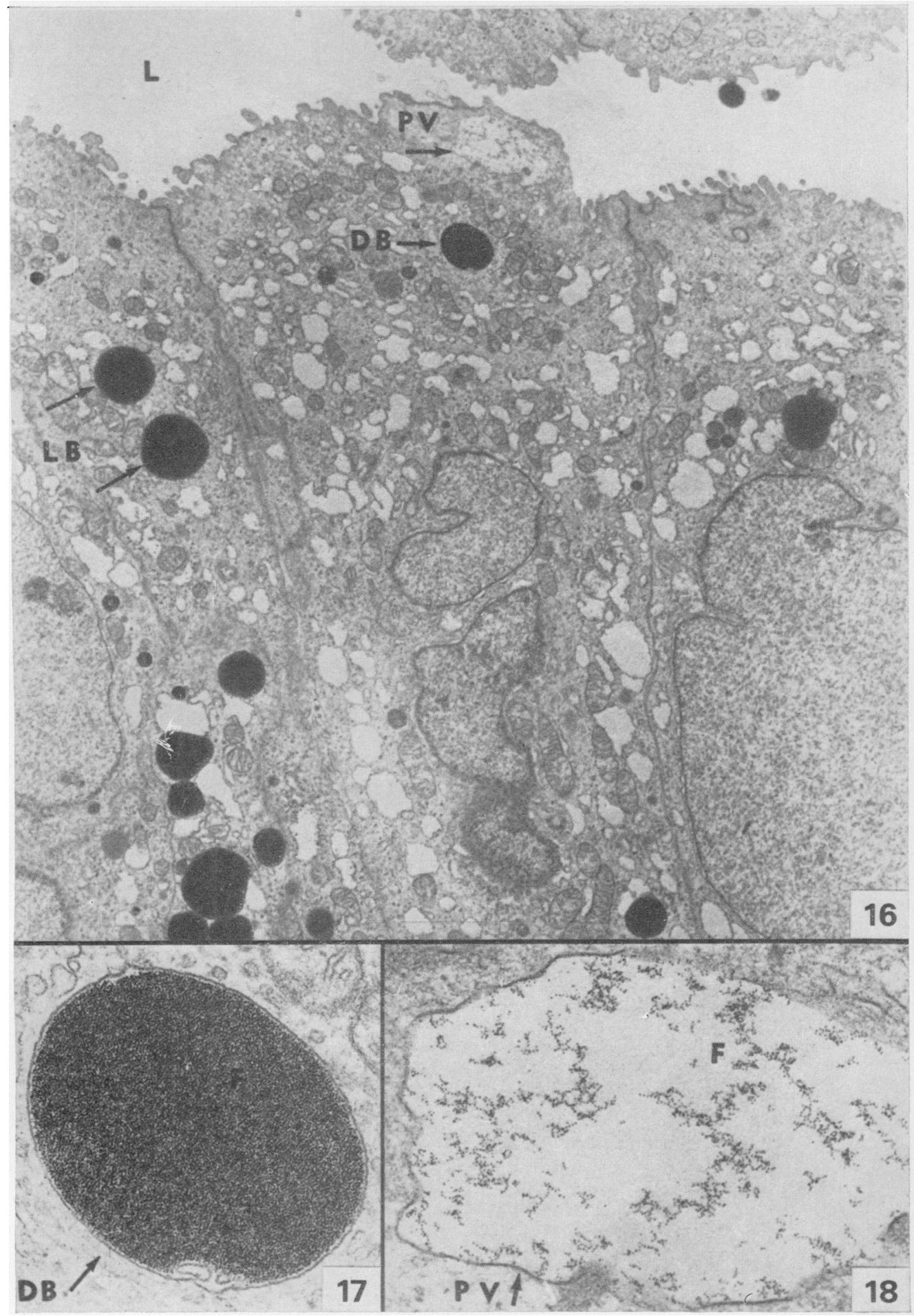


In mice, pinopods were present in the uterine epithelium on Day 4 of normal pregnancy and during delayed implantation, but not on Days 2, 3 and 5 of pregnancy or after oestrogen administration to animals in delayed implantation. It is evident that pinopods develop and are maintained in the endocrine environment of the early luteal phase, as noted by Bergstrom \& Nilsson (1972), and that they are inhibited by exogenous oestrogen or by the normal increased oestrogen level on Day 4 of pregnancy (McCormack \& Greenwald, 1974). The control of pinopod formation in the mouse is analogous to that found in the rat, in which pinopods were found on Day 5 of pregnancy and during delayed implantation, but not on Day 6 of pregnancy or after oestrogen treatment of animals in delayed implantation (Warren \& Enders, 1964; Nilsson, 1966; Enders \& Nelson, 1973; Parr \& Parr, 1974). In addition, the overall endocytosis of ferritin by rat uterine epithelium has been found to be stimulated by progesterone and blocked by oestrogen (Leroy, Van Hoeck \& Bogert, 1976).

The incorporation of ferritin into the pinopod vacuoles of mouse and rat uterine epithelial cells shows that the cells are undergoing endocytosis, rather than apocrine secretion, at a time during pregnancy when unimplanted embryos are present in the uterine lumen. The process is terminated as implantation begins. Studying mice in delayed implantation, Bergstrom (1972) and Bergstrom \& Nilsson (1973) observed the presence of crater-like imprints on the surface of the blastocyst which they believed were caused by the fungus-like protrusions from the apices of the epithelial cells. When progesterone was withdrawn, the crater-like imprints disappeared as did the fungus-like protrusions and blastocyst viability. They suggested that the protrusions were probably involved in the nutrition of the blastocyst. Other suggestions have also been put forward for the possible role of endocytosis during this period (Enders \& Nelson, 1973; Parr \& Parr, 1974; Leroy et al., 1976), but its function remains unknown.

\section{References}

AlTKEN, R.J. (1975) Ultrastructure of the blastocyst and endometrium of the roe deer during delayed implantation. J. Anat. 119, 369-384.

BergStrom, S. (1972) Delay of blastocyst implantation in the mouse by ovariectomy or lactation. A scanning electron microscope study. Fert. Steril. 23, 548-561.

Bergstrom, S. \& Nilsson, O. (1972) Ultrastructural response of blastocysts and uterine epithelium to progesterone deprivation during delayed implantation in the mouse. J. Endocr. 55, 217-218.

Bergstrom, S. \& Nilsson, O. (1973) Various types of embryo-endometrial contacts during delay of implantation in the mouse. J. Reprod. Fert. 32, 531533.

Enders, A.D. \& Nelson, D.M. (1973) Pinocytic activity of the uterus of the rat. Am. J. Anat. 138, 277-300.

Leroy, F., Van Hoeck, J. \& Bogert, C. (1976) Hormonal control of pinocytosis in the uterine epithelium of the rat. J. Reprod. Fert. 47, 59-62.

Löör, L., Nilsson, O. \& Toss, G. (1968) Ultrastructure and ATPase activity of rat uterine epithelium during blastocyst attachment. Fert. Steril. 19, 435-441.

McCormacx, J.T. \& Greenwald, S.G. (1974) Progesterone and oestradiol-17 $\beta$ concentrations in the peripheral plasma during pregnancy in the mouse. J. Endocr. 62, 101-107.

NiLsson, O. (1962) Correlation of structure to function of the luminal cell surface in the uterine epithelium of mouse and man. Z. Zellforsch. mikrosk. Anat. 56, 803-808.

NiLsson, O. (1966) Structural differentiation of luminal membrane in the rat uterus during normal and experimental implantations. Z. Anat. EntwGesch. $125,152-159$.

NiLsson, O. (1972) Ultrastructure of the process of secretion in the rat uterine epithelium at preimplantation. J. Ultrastruct. Res. 40, 572.

Nilsson, O. \& NYGREN. K.G. (1974) Ultrastructure of human uterine epithelium at the time of implantation after postovulatory administration of norethindrone. Upsala J. med. Sci. 79, 65-71.

Parr, E.L. (1973) Shedding of the zona pellucida by guinea pig blastocysts: an ultrastructural study. Biol. Reprod. 8, 531-544.

Parr, M.B. \& PARr, E.L. (1974) Uterine luminal epithelium: protrusions mediate endocytosis, not apocrine secretion, in the rat. Biol. Reprod. 11, 220233.

Psychoyos, A. \& MANdon, P. (1971) Etude de la surface de l'epithelium uterin au microscope electronique à bayalage. Observations chez la Ratte au $4^{\boldsymbol{c}}$ et au $5^{\mathrm{e}}$ jour de la gestation. C. r. hebd. Séanc. Acad. Sci., Paris 272, 2723-2725.

WARREN, R.H. \& ENDERS, A.C. (1964) An electron microscope study of the rat endometrium during delayed implantation. Anat. Rec. 148, 177-195. 